\title{
Binding Modes of Doxorubicin Compared to Estratetrol and Tamoxifen
}

\author{
Muchammad R. Ghozaly ${ }^{1}$, Ellin Febrina ${ }^{1}$, Achmad Zaenudin ${ }^{2}$ \\ ${ }^{1}$ Department of Pharmacology and Clinical Pharmacy, Faculty of Pharmacy, Universitas Padjadjaran, \\ Jatinangor, West Java, Indonesia \\ ${ }^{2}$ Department of Chemistry, Faculty of Mathematics and Natural Sciences, Universitas Padjadjaran, \\ Jatinangor, West Java, Indonesia.
}

\begin{abstract}
Doxorubicin, a compound isolated from Streptomyces peucetius var Caesius, is commonly used in the treatment of breast cancer. This drug works by interacting on human nucleic acids. This work was aimed to study the binding modes of doxorubicin with estrogen receptor alpha $(\mathrm{ER} \alpha)$. Estratetrol and tamoxifen were used as natural ligand and standard drug, respectively. Molecular docking simulations was performed by AutoDock v.3.05 using minimum coordinates $-34,-6,-15(\mathrm{x}, \mathrm{y}, \mathrm{z})$ and the maximum coordinates $-13,13,3(\mathrm{x}, \mathrm{y}, \mathrm{z})$. Tamoxifen formed one hydrogen bond with Glu353 $(\mathrm{Ki}=3.78 \mu \mathrm{M})$; estratetrol binds to Glu353, Arg394, Gly521, and His524 (Ki=0.01 $\mu \mathrm{M})$. Doxorubicin only formed one hydrogen bond with Ser317 $(\mathrm{Ki}=\mathrm{N} / \mathrm{A})$. In conclusion, doxorubicin could not interact appropriately with ER $\alpha$ due to its voluminioues structure which hinder its entrance to binding pocket of the macromolecule.
\end{abstract}

Keywords: doxorubicin, estrogen receptor alpha.

\section{Introduction}

World Health Organization (WHO) states $8-9 \%$ of women in the world are at risk of breast cancer. This makes breast cancer the most common type of cancer in women. Every year more than 250,000 new cases of breast cancer are diagnosed in Europe and about 17000 in the United States. Data collected in hospitals showed that breast cancer was ranked first among other cancers in women in Indonesia. ${ }^{1,2}$

Estrogen hormone is one of the sex hormone steroids, because it has a steroid-like chemical structure that is physiologically produced mostly by the endocrine glands of the female production system. Men also produce estrogen but in much smaller amounts. Its primary function is closely related to the function of the primary and female genitalia ${ }^{3}$ Estrogen has two types of receptors, namely $\mathrm{ER} \alpha$ and ER $\beta$ derived from different genes and located in the cell nucleus. The estrogen receptor (ER) is a ligand activated transcription factor that can increase or decrease the mRNA synthesis of the target gene depending on the compound it occupies. ER $\alpha$ plays a major role in breast cancer because of its large number in breast compared to ER $\beta$. . ER $\alpha$ is a heterotetramer

Corresponding author: Muchammad R. Ghozaly, Department of Pharmacology and Clinical Pharmacy, Faculty of Pharmacy, Universitas Padjadjaran, Jatinangor, West Java, Indonesia. Email: rhezaghozali@, yahoo.com 
with 4 different types of monomer ${ }^{4}$

Doxorubicin is an anthracycline antibiotic. It is widely used for the treatment of various types of cancer due to its interaction with nucleic acids. Doxorubicin is also known as adriamicin. However, the information regarding its effectiveness in breast cancer treatment was limited. ${ }^{5}$

This study was aimed to compare the compare the binding mode of doxorubicin with estratetrol to discover anti-breast cancer drug.

\section{Methods}

\section{Tools and materials}

The hardware used for molecular calculation, molecular modeling and docking included a personal computer with Windows XPTM Home Basic (2009) operating with an Intel Dual Core Genuine CPU CPU E5300 $2.60 \mathrm{GHZ}$, Windows XPTM Home Basic operating system ( 2010), 80 GB hard disk capacity, and 1 GB RAM memory.

1. ChemOffice 2004.

2. HyperChem Release 8.0.7.

3. SwissPDBViewer v.4.0.1

4. AutoDock v.3.05 in MGLTools v.1.5.4

5. ArgusLab v.4.0.1

6. Ligand Explorer Viewer v.3.8

3D structure of ER $\alpha$ was downloaded from www.pdb.org (code: 3LO3). 2D and 3D structure of doxorubicin was built using the ChemOffice 2004.

\section{Method}

1. Geometry optimization and analysis of molecular properties of doxorubicin performed using Hyperchem Release 8.0.7

2. Reduction of ER $\alpha$ receptor chain into its monomer form using SwissPDBViewer v4.01.

3. Analysis of a binding pocket was performed using Ligand Explorer Viewer v.3.8.

4. Validation of software.

5. Molecular docking simulation of doxorubicin was performed by using Autodock v3.05.

\section{Results and Discussion}

Preparation of ligands is an early stage in the docking process. Preparation of ligand serves to prepare ligands used in the docking process in order to have a conformation in accordance with the actual situation in nature. Preparation of ligands consists of several stages, including the making of twoand three-dimensional structures, geometric optimization, and molecular properties analysis. Conformational changes before and after gemoetry optimization was shown in Figure 1.

The cLog P of doxorubicin compounds was smallest compared to the other ligands, indicating lipophilicity property. Doxorubicin is more polar, hence it will be easier to be distributed in the circulation. Based on this character, doxorubicin was predicted could not interact with the non-polar character of hydrophobic ER $\alpha$ binding pocket.

Table 2 provides the number of HBD and HBA of the ligands. According to the Lipinski Rule of five principle, a compound can be used as a drug with peroral route if it has a maximum of 5 donors and ten acceptor hydrogen bonds.

The number of HBD and HBA also determines the ability of a compound to bind with the amino acid residue via hydrogen bonding. The more hydrogen bonds are formed, the stronger the bond between the receptor ligand. ${ }^{6}$

Preparation of ER $\alpha$ showed that this macromolecule is a heterotetramer structure, 

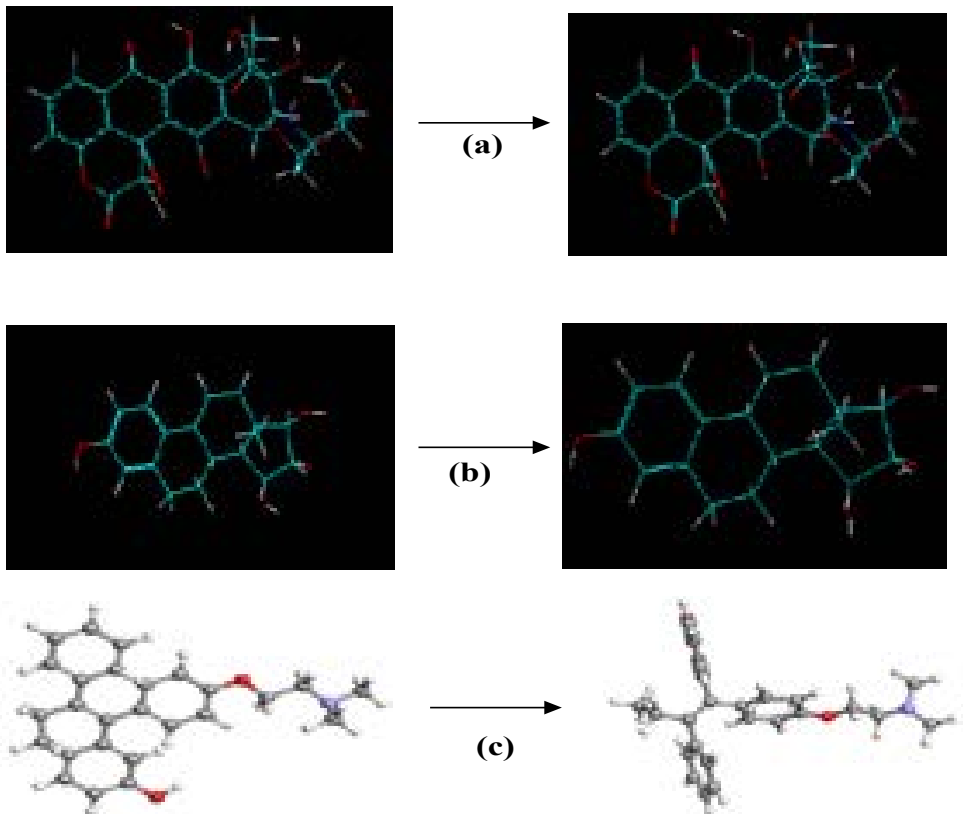

Figure 1. Geomety optimization of a) doxorubicin b) estratetrol c) tamoxifen

consist of four different monomers (chan A, chan $\mathrm{B}$, chan $\mathrm{C}$, chain $\mathrm{D})$. Estratetrol was observed bound to chain $\mathrm{A}$.

The minimum coordinates of ER $\alpha$ binding pocket at $-34,-6,-15(\mathrm{x}, \mathrm{y}, \mathrm{z})$ and the maximum coordinates are at $-13,13,3(\mathrm{x}, \mathrm{y}$, $\mathrm{z}$ ). The area between the minimum and the maximum is the active receptor side region with a volume of $460 \AA 3$.

Geometry optimization results of both estratetrol molecules were overlayed and calculated its Root Mean Square Deviation (RMSD). A model compound is considered to have a structural similarity with its crystalline ligand if the RMSD value was less than two. The RMSD value of the overlay was $1.79 \AA$, meaning that the RMSD value meets the requirements of less than two and it can be said that the estratetrol structure of the model is close to the crystalline estratetrol structure.

Table 3 shows the comparison between crystallized estratetrol and its model. The results showed that their interaction energy (EI), inhibition constants (Ki), and hydrogen bonds were relatively similar. Six amino acids were available in the re-docking of crystallized estratetrol i.e., Glu353, Met388, Arg394, Phe404, Ile424, and His524. In its model, there were three additional amino acids: Leu384, Leu387, and Gly521. There was no significant difference between the crystallized estratetrol profile and its model. Therefore, it can be concluded that the program AutoDockTools v.3.05 is valid.

Table 1. Analysis of molecular characteristics

\begin{tabular}{lcccc}
\hline \multicolumn{1}{c}{ Ligand } & Energy (kcal/mol) & cLog $\mathbf{P}$ & Volume $\left(\AA^{\mathbf{3}}\right)$ & Mass $(\mathbf{a m u})$ \\
\hline Doxorubicin & -7572.18 & -0.08 & 1323.64 & 571.54 \\
Estratetrol & -4761.69 & 2.54 & 846.58 & 304.39 \\
Tamoxifen & -6181.30 & 1.85 & 1211.00 & 387.52 \\
\hline
\end{tabular}


Table 2. Prediction of hydrogen bonds donor (HBD) and acceptor (HBA)

\begin{tabular}{lccc}
\hline \multicolumn{1}{c}{ Ligand } & HBD & HBA & Aromatic ring \\
\hline Doxorubicin & 5 & 6 & 4 \\
Estratetrol & 2 & 2 & 1 \\
Tamoxifen & 1 & 3 & 3 \\
\hline
\end{tabular}

EI is the energy required by a ligand to enter and bind to its receptor. EI of tamoxifen and estradiol were negative, showing that they can bind to the receptors spontaneously without energy, while doxorubicin was positive. Doxorubicin needs a lot of energy to bind freely to the receptors. The amount of free energy influences the magnitude of the $\mathrm{Ki}$. The lower the free energy, the lower the value of $\mathrm{Ki}^{7,8}$

The number of hydrogen bonds on ligandreceptor interactions depends on the presence of $\mathrm{H}, \mathrm{O}, \mathrm{N}$, or $\mathrm{S}$ atoms surrounding the ligand. Atom $\mathrm{H}$ acts as a hydrogen bonding donor, while the $\mathrm{O}, \mathrm{N}$, and $\mathrm{S}$ atoms act as hydrogen bond acceptor. ${ }^{9}$ Amino acid residues are amino acids around the ligands at a certain

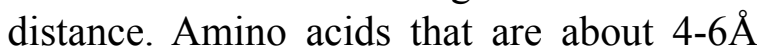
will form the interaction of van der Waals. Van der Waals interactions have an effect on the solubility of a ligand in lipids. The more van der Waals interactions formed, the higher the solubility in lipids. In addition, this interaction also plays a role in the strength of ligand-receptor interactions. ${ }^{10-12}$ Table 5

Table 3. Docking and re-docking of estratetrol

\begin{tabular}{lccc}
\hline \multicolumn{1}{c}{ Parameter } & Replication & Crystallized Estratetrol & Estratetrol Model \\
\hline EI (kkal/mol) & 1 & -4.22 & -4.21 \\
& 2 & -4.23 & -4.23 \\
& 3 & -4.25 & -4.19 \\
\hline Ki (M) & 1 & 0.000935 & 0.000933 \\
& 2 & 0.000963 & 0.000967 \\
& 3 & 0.000967 & 0.000955 \\
\hline Hydrogen bond distance & 1 & $1.627 \AA$ & $1.928 \AA$ \\
& 2 & $1.995 \AA$ & $2.081 \AA$ \\
Amono acid residues & 3 & $2.217 \AA$ & $2.035 \AA$ \\
& 1 & Glu353, Met388, & Glu353, Leu384, \\
& & Arg394, Phe404, & Leu387, Met388, \\
& & Ile424, His524 & Leu391, Arg394, \\
& & & Ile424, Gly521, His524 \\
& \multirow{2}{*}{2} & Glu353, Met388, & Glu353, Leu384, \\
& & Arg394, Phe404, & Leu387, Met388, \\
& & Ile424, His524 & Leu391, Arg394, \\
& & & Ile424, Gly521, His524 \\
& \multirow{2}{*}{3} & Glu353, Met388, & Glu353, Leu384, \\
& Arg394, Phe404, & Leu387, Met388, \\
& Ile424, His524 & Leu391, Arg394, \\
& & & Ile424, Gly521, His524 \\
\hline
\end{tabular}


Table 4. Results of Docking Simulation

\begin{tabular}{lccc}
\hline \multicolumn{1}{c}{ Parameter } & Doxorubicin & Tamoxifen & Estratetrol \\
\hline EI & 1104.254 & -8.90 & -10.74 \\
\hline Ki & 0.00 & 3.78 & 0.0108 \\
\hline Hydrogen bond & & & H-est..O- Glu353 \\
& H-dox.. O- Ser317 & $\neg-$ O-est..H- Arg394 \\
& & & H-est..O- Gly521 O- \\
tin..H- His524
\end{tabular}

shows that all ligands have several van der Waals interactions, indicating that the ligandreceptor bond is strong.

\section{Conclusion}

Doxorubicin could not interact appropriately with ER $\alpha$ due to its voluminious structure which hinder its entrance to binding pocket of the macromolecule.

\section{Acknowledgement}

None declared

\section{Funding}

This study was not funded by any source of grants

\section{Conflict of Interest}

The authors declared no potential conflicts of interest with respect to the research authorship, and/or publication of this article

\section{References}

1. Kocic B, Filipovic S, Petrovic B, Mijalkovic D, Rancic N, Poultsidi A. Clinical and biological characteristics of breast cancer. Journal of Balkan Union.
2010;15:660-667.

2. Mukherjee S, Chatterjee G, Ghosh M, Das B, Majumder D. Efficacy and toxicity assessment of different antibody based antiangiogenic drugs by computational docking method. Advances in Bioinformatics. 2016;2016:705-712.

3. Lee J.-M., Sarosy G. A., Annunziata C. M., et al. Combination therapy: intermittent sorafenib with bevacizumab yields activity and decreased toxicity. British Journal of Cancer. 2010;102(3):495499.

4. Banerjee S, Dowsett M, Ashworth A, Martin L. Mechanisms of disease: angiogenesis and the management of breast cancer. Nature Clinical Practice Oncology. 2007;4(9):536-550

5. Chewchuk S, Guo B, Parissenti AM. Alterations in estrogen signalling pathways upon acquisition of anthracycline resistance in breast tumor cells. PLoS ONE. 2017;12(2): e0172244.

6. Siwek A, Stączek P, Wujec M, Bielawski K. Cytotoxic effect and molecular docking of 4-ethoxycarbonylmethyl-1-(piperidin4-ylcarbonyl)-thiosemicarbazide-a 
novel topoisomerase II inhibitor. Journal of Molecular Modeling. 2013;19(3):13191324.

7. Pritchard JE, Dillon PM, Conaway MR, Silva CM, Parsons SJ. A Mechanistic study of the effect of doxorubicin/ adriamycin on the estrogen response in a breast cancer model. Oncology. 2012;83(6):305-320.

8. Yousuf Z, Iman K, Iftikhar N, Mirza MU. Structure-based virtual screening and molecular docking for the identification of potential multi-targeted inhibitors against breast cancer. Breast Cancer: Targets and Therapy. 2017;9:447-459.

9. Li CI, Beaber EF, Tang MT. Reproductive factors and risk of estrogen receptor positive, triple-negative, and HER2-neu overexpressing breast cancer among women. Breast Cancer Research and
Treatment. 2013;137(2):579-587.

10. Suganya J, Radha M, Naorem DL, Nishandhini M. In Silico docking studies of selected flavonoids-natural healing agents against breast cancer. Asian Pacific Journal of Cancer Preview. 2014;15:8155-8159.

11. Singh AN, Baruah MM, Sharma N. Structure Based docking studies towards exploring potential anti-androgen activity of selected phytochemicals against Prostate Cancer. Scientific Reports. 2017;7:19-55.

12. Khan SN, Khan AU. An in silico approach to map the binding site of doxorubicin on hemoglobin. Bioinformation. 2008;2(9):401-404. 